\title{
Non-involvement of the accessory olfactory system in the LH response of anoestrous ewes to male odour*
}

\author{
J. Cohen-Tannoudji, C. Lavenet, A. Locatelli, Y. Tillet and J. P. Signoret \\ INRA, Reproductive Physiology, 37380 Monnaie, France
}

\begin{abstract}
Summary. In anoestrous ewes, male chemosignals elicit rapid increases in luteinizing hormone (LH) secretion that can ultimately lead to ovulation. To assess the possible involvement of the accessory (vomeronasal) olfactory system in the mediation of those chemical cues, we destroyed this pathway by vomeronasal organ electrocauterization (Exp. I) and vomeronasal nerve section (Exp. II). Neither of these lesions inhibited the LH response of ewes to the odour of the male. These results suggest that the vomeronasal system is not necessary to mediate the neuroendocrine response of the ewe to the male odour. As both surgical methods spared the main olfactory system but destroyed the vomeronasal system, it is likely that the main olfactory system is involved in the $\mathrm{LH}$ response to chemical stimulation in sexually experienced ewes.
\end{abstract}

Keywords: sheep; male effect; chemosignals; vomeronasal system

\section{Introduction}

Chemical cues markedly influence reproductive processes in mammals. They elicit sex attraction and copulatory behaviour but also profoundly modulate reproductive physiology (Keverne, 1977; Marchlewska-Koj, 1984). Compounds emitted by females induce endocrine responses in males such as luteinizing hormone $(\mathrm{LH})$ or testosterone release (Macrides et al., 1974; Maruniak \& Bronson, 1976). Male chemosignals regulate cyclicity of females of numerous species (Marchlewska-Koj, 1984). For instance, in mice, a urinary signal from males accelerates puberty in young females (Colby \& Vandenbergh, 1974) and induces pregnancy block (Dominic, 1964) or oestrus cyclicity of females housed in groups (Bronson \& Whitten, 1968). In all those 3 effects, male chemosignals first stimulate neuroendocrine mechanisms since they induce a rapid change in $\mathrm{LH}$ or prolactin secretion in the female (Keverne, 1983; Bronson \& Macmillan, 1984).

Numerous studies have been undertaken to determine the olfactory pathways involved. In rodents, the accessory (vomeronasal) system appears to be primarily implicated in the perception of signals acting on neuroendocrine mechanisms. Disrupting the vomeronasal system in mice effectively suppresses the 3 physiological responses of female mice to the male (Reynolds \& Keverne, 1979; Bellringer et al., 1980; Lomas \& Keverne, 1982) and it also suppresses endocrine responses of males to female cues (Wysocki et al., 1983; Coquelin et al., 1984).

In sheep, endocrine effects mediated through the olfactory pathway have been demonstrated. The introduction of a ram induces very rapid increase in LH secretion of previously isolated anoestrous ewes (Martin et al., 1978; Poindron et al., 1980). This enhanced secretion will ultimately lead to ovulation and oestrus if stimulation is maintained. Male fleece (Knight \& Lynch, 1980; Signoret \& Lindsay, 1982) or wool extracts (Knight \& Lynch, 1980) mimic the male effect, which is thus primarily achieved by chemical stimuli.

This male effect in sheep, because of its chemosensory basis and its rapidity, appears quite similar to what has been observed in rodents. This, together with the fact that the vomeronasal

\footnotetext{
*Reprint requests to: J. P. Signoret.
} 
organ is present and functional in ungulates (Kratzing, 1971; Ladewig \& Hart, 1981), led us to suggest that the LH response in the ewe might be mediated by the accessory system.

The aim of this experiment was therefore to study the effects of accessory pathway lesions on the $\mathrm{LH}$ response of ewes to the odour of rams. As no lesions of the accessory olfactory system had previously been undertaken in sheep, two different surgical methods were designed to assess the possible role of the vomeronasal pathway.

\section{Materials and Methods}

\section{Animals}

In Exp. I, the sheep were 32 sexually experienced females of the Ile-de-France breed, of 3-6 years of age. They were isolated from males for at least 1 month and housed in a building which had not contained rams previously. They were fed a dehydrated concentrate (maize and lucerne) once daily, with wheat straw and mineral complement ad libitum.

The ewes were diagnosed as seasonally anovulatory by weekly progesterone assays (Terqui \& Thimonier, 1975), the persistence of low concentrations of circulating progesterone indicating the absence of functional corpora lutea.

The ewes were randomly allocated to three experimental groups: (1) lesion of the vomeronasal organ $(\mathrm{N}=12)$; (2) sham-operation $(\mathrm{N}=8) ;(3)$ intact controls $(\mathrm{N}=12)$.

In Exp. II, 26 sexually experienced adult Ile-de-France ewes of 5-8 years of age were used in the same conditions as those of Exp. I. They were randomly allocated to three experimental groups: (1) section of the vomeronasal nerves $(\mathrm{N}=10)$; (2) sham-operation $(\mathrm{N}=6) ;(3)$ intact controls $(\mathrm{N}=10)$.

\section{Surgery}

Experiment I: vomeronasal organ lesion.

Vomeronasal organs in sheep are very large and visible structures. They consist of two epithelial tubes of $\sim 8 \mathrm{~cm}$ long, surrounded by a vomeronasal cartilage of $1 \mathrm{~cm}$ height, lying on either side of the base of the basal septum (Fig. la). Such structures are easily accessible for destruction. We developed a surgical method that gives access to the vomeronasal organ via the upper part of the nose and destroys it without damaging the highly vascularized nasal turbinates (see Fig. Ia). Anaesthesia was induced by pentobarbitone sodium and maintained with fluothane-oxygen given via an intratracheal tube. The frontal bone was drilled medially $4 \mathrm{~cm}$ from either side of the middle line of the first lower teeth. A diathermic cutting tool was gently introduced between the nasal septum and the turbinate up to the vomeronasal organ and then the organ was cauterized along its full length. The same operation was repeated on the other side of the nasal cavity. In the sham-operated animals, the surgical procedure was identical, but the cutting tool was switched off when moved along the vomeronasal organ. One month was allowed for recovery which was uneventful: all ewes survived and appeared in good condition.

Experiment $I I$ : vomeronasal nerves section.

The vomeronasal 'nerves in the sheep course ventrally and apically onto the septum and then pass through the cribriform plate. After entering the cranial cavity, they unite into one nerve that bends around the margin of each olfactory bulb and terminates in the accessory olfactory bulbs located medio-dorsally on the main bulb surface (see Fig. 1b).

We aimed to cut the nerves just before their entrance into the cranial cavity through the cribriform plate. After anaesthesia as in Exp. I, the frontal bone was removed through a triangular incision beginning dorsally on the horizontal plane between the eyes and ending $6 \mathrm{~cm}$ below. This exposed the frontal sinus and the posterior end of the nasal septum.

A hole was drilled in the nasal septum forward to and between the olfactory bulbs in order to destroy about $1 \mathrm{~cm}$ of the vomeronasal nerves when they pass across the nasal septum (see Fig. 1b). As the main olfactory bulbs are about $1 \mathrm{~cm}$ apart in this species, the surgical approach may only cause minor damage to the olfactory nerves. After the hole was drilled, the ends of the sectioned vomeronasal nerves were systematically sought and observed with a surgical microscope to verify the completeness of the section. As in Exp. I, recovery lasted 1 month, and was uneventful.

\section{Anatomical and histological assessment of the vomeronasal lesions}

Histological analysis was undertaken to verify the orthograde degeneration of neuroreceptor axons in the glomeruli of the accessory olfactory bulbs. For both experiments, animals were killed 5 months after the experiment and heads were perfused with $10 \%$ phosphate buffered formalin. The olfactory bulbs were removed and stored for at least several days in $10 \%$ phosphate buffered formalin and then transferred to sucrose $(15 \%)$. They were cut at $15 \mu \mathrm{m}$ in the transverse plane with a cryomicrotome and the sections were stained with cresyl violet acetate.

For animals of Exp. I, the anterior part of the head was also dissected and the nasal septum was exposed to verify vomeronasal organ destruction. 


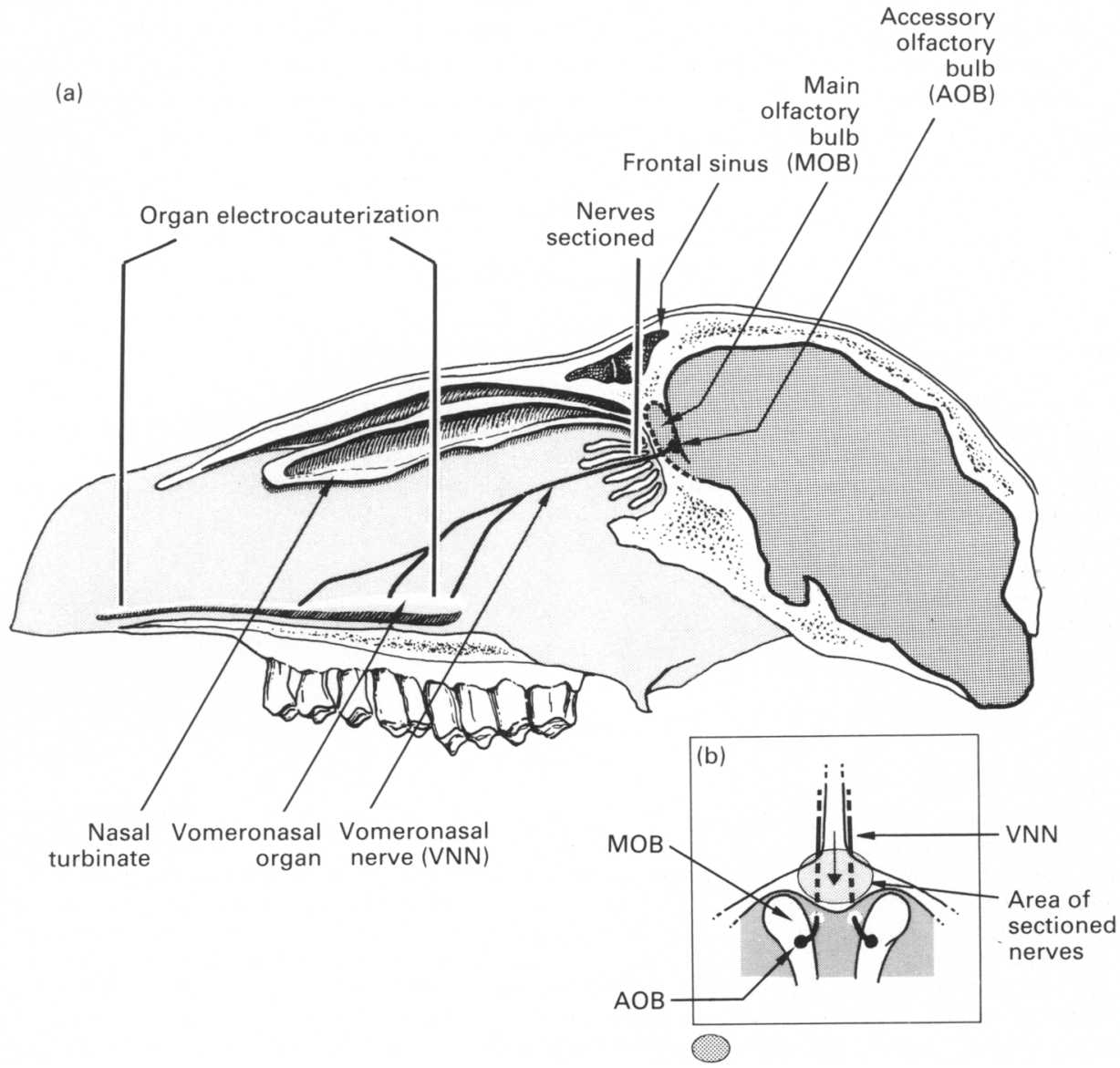

Fig. 1. Vomeronasal lesions in sheep; schematic representation of a parasagittal section through the ewe nasal cavity. The vomeronasal system was lesioned by electrocauterizing the organ in the nasal cavity (Exp. I) or by sectionning the nerves (b) just before their entrance to the cranial cavity (Exp. II).

The fluorescent dye rhodamine-B-isothiocyanate (RITC: Sigma, St Louis, MO., USA) was used to verify that section of the vomeronasal nerves effectively led to vomeronasal system deafferentation. The transport of RITC was first examined in a control animal. The anaesthetized ewe was placed in a supine position and a catheter was inserted, via the nasopalatine duct, into each vomeronasal organ. A $2 \cdot 5 \%$ solution of RITC (50:1) was then injected into the lumen of each organ. The animal was killed 12 days later. The time taken for the dye to reach the accessory olfactory bulbs was estimated from observations of Thanos et al. (1987) on the visual system of the rat. The head was then perfused with $10 \%$ phosphate buffered formalin, the olfactory bulbs and the vomeronasal organs removed and cut at $15 \mu \mathrm{m}$ with a cryomicrotome. The glycerol-mounted preparations were then examined under a Leitz fluorescence microscope (wavelength; excitation: $545 \mathrm{~nm}$, observation: $580 \mathrm{~nm}$ ).

The same procedure was repeated on 2 other ewes in which the vomeronasal nerves had been sectioned 3 days and 1 month earlier.

\section{Olfactory discrimination test}

In both experiments, animals were allowed to recover for 1 week after surgery and then tested for olfactory discrimination. To verify that general olfaction was not impaired by surgery, olfactory ability was measured by a repulsion test as described by Poindron (1974). This consisted of a feeding choice test between two troughs, one containing only lucerne pellets, the other containing lucerne pellets placed on a grid over dog faeces (known to be very repulsive to sheep) lying below. Intact ewes are strongly repelled by dog faeces and never eat from this trough whereas anosmic ewes indiscriminately eat from both troughs (Poindron, 1974; Cohen-Tannoudji et al., 1986). 


\section{$L H$ response to ram's odour}

Ewes in both experiments were stimulated by ram's wool 1 month after surgery. Blood samples $(5 \mathrm{ml})$ were collected at 20 -min intervals by jugular venepuncture for $5 \mathrm{~h}$, involving a pre-stimulation period of $2 \mathrm{~h}$ and an olfactory stimulation period of $3 \mathrm{~h}$. This stimulation was achieved by fitting the ewes with masks containing ram's wool as previously described (Cohen-Tannoudji et al., 1986). Preliminary experiments have shown that the masks had no effect on LH pulsatility by themselves. After centrifugation, plasma was stored at $-15^{\circ} \mathrm{C}$ until LH radioimmunoassay. Concentrations of LH were measured in duplicate samples of 100:1 plasma by a double-antibody radioimmunoassay (Pelletier et al., 1982) modified from that of Pelletier et al. (1968). The assay was conducted by displacement. The activity of the standard (M3 CNRS) was $1.8 \mathrm{iu} / \mathrm{mg} \mathrm{NIH-LH-S1} \mathrm{(M.} \mathrm{Jutisz,} \mathrm{CNRS,} \mathrm{Gif} \mathrm{sur} \mathrm{Yvette,}$ France). The sensitivity of the assay was $0.2 \mathrm{ng} / \mathrm{ml}$, the within-assay coefficient of variation was $<10 \%$ and the non-specific binding was $<5 \%$.

Pulses of LH were defined as a rise of LH according to the following criteria (adapted from Martin et al., 1983): (i) both the increase and subsequent decrease in concentration had to exceed the sum of the assay errors appropriate for the concentrations at the onset and the peak of the pulse; (ii) the increase had to occupy no more than two sampling intervals and the decline had to begin within two sampling intervals of attainment of the peak.

The assay error was estimated from the coefficient of variation determined from the standard curve.

The increase in LH pulsatility was used to test the female response. This response is easily estimated in tle-de-France ewes as they present a very low spontaneous pulsatility during the anoestrous season $(1.7$ pulses $/ 12 \mathrm{~h}$ : Montgomery et al., 1985).

In most cases, we observed that the pre-stimulation period was devoid of LH pulses and the response was then simply characterized by the occurrence of one, sometimes two, pulses after odour stimulation. The number of responsive ewes, i.e., those with an increased number of pulses between the $2 \mathrm{~h}$ before and after odour stimulation, was determined for each group and compared between groups by the Fisher exact probability test (Siegel, 1956).

\section{Results}

\section{$L H$ response to ram's odour}

Experiment 1 . Lesion of the vomeronasal organ in ewes did not prevent their endocrine response to male odour as a majority of females (7/12) exhibited an increase in pulsatility after stimulation (Fig. 2 and Table 1). The number of responsive females did not significantly differ between the operated and control group (7/12 vs $8 / 12$, Fisher test, $P>0 \cdot 1$ ). The proportion of responsive females in the sham-operated group was lower $(2 / 8)$ but did not differ significantly from the other two groups (Fisher test, $P>0 \cdot 1$ ).

Experiment II. The results (Table 1), were similar to those obtained in Exp. I. Although the accessory olfactory system had been impaired, a proportion of ewes still responded to the male's odour with a significant increase in LH pulsatility (Table 1). The LH patterns (Fig. 2) were similar in all 3 groups and the number of responsive females did not differ between groups (Fisher test, $P>0 \cdot 1)$.

Table 1. Effects of lesion of the accessory olfactory system on $\mathrm{LH}$ response of ewes to male odour

\begin{tabular}{lccc}
\hline & \multicolumn{3}{c}{ Proportion of responsive females } \\
\cline { 2 - 4 } & $\begin{array}{c}\text { Operated } \\
\text { group }\end{array}$ & $\begin{array}{c}\text { Control } \\
\text { group }\end{array}$ & $\begin{array}{c}\text { Sham-operated } \\
\text { group }\end{array}$ \\
\hline $\begin{array}{l}\text { Exp. I: Lesion of } \\
\text { vomeronasal organ }\end{array}$ & $7 / 12$ & $8 / 12$ & $2 / 8$ \\
\hline $\begin{array}{l}\text { Exp. II: Section of } \\
\text { vomeronasal nerves }\end{array}$ & $7 / 10$ & $7 / 10$ & $3 / 6$ \\
\hline
\end{tabular}

\section{Assessment of the effectiveness of the lesion}

In both experiments, the repulsive trough was repellent for the ewes in all 3 groups, showing that general olfactory perception had not been impaired after vomeronasal lesions. 


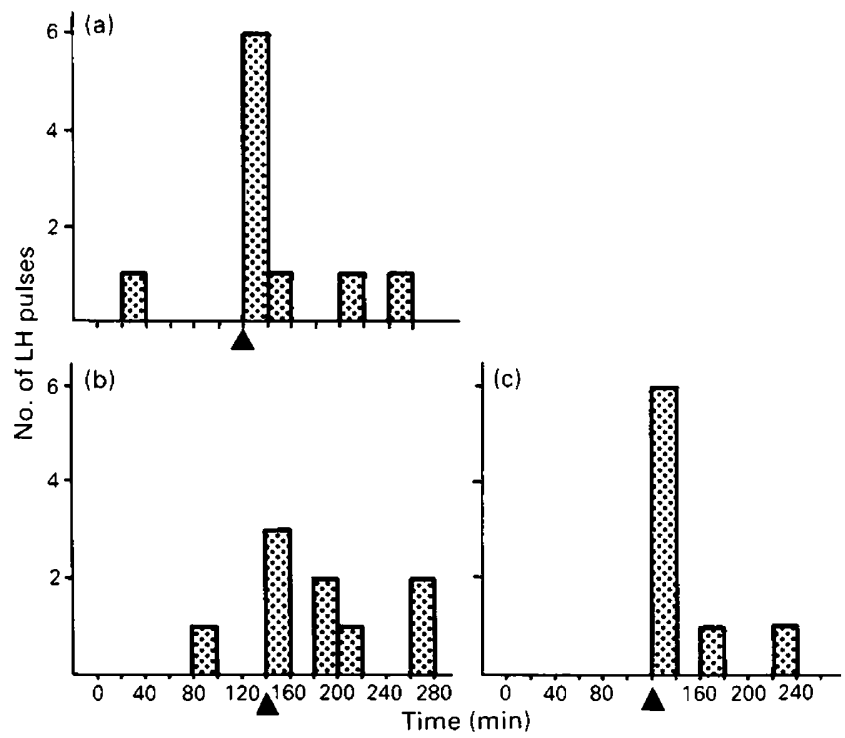

Fig. 2. LH responses to male odour of control ewes (a, Exp. I) and ewes in which the vomeronasal organ had been cauterized (b, Exp. I) or the nerves sectioned (c, Exp. II). Histograms represent the summation of all the LH pulses observed in the group. The black triangle indicates the onset of odour stimulation.

Head dissection of vomeronasalectomized animals in Exp. I showed that the vomeronasal organ had been entirely burnt away. No trace of vomeronasal epithelium or even cartilage could be found. All the structure had undergone necrosis (Fig. 3) and, in most cases, the basal part of the nasal septum had even disappeared.

For both vomeronasalectomized groups, the nerves were no longer visible ending in the accessory bulbs and the glomerular layer was very shrunken and disorganized (Fig. 4).

However, in both experiments, the glomerular layer of sham-operated or control ewes was intact and vomeronasal nerves could be seen terminating in the accessory bulb glomeruli (Fig. 4).

The use of anterograde transport of a fluorescent dye indicates the effectiveness of nerve section. After RITC injection into the vomeronasal organs of the control animal, the dye was incorporated in the neuroreceptors and transported in the accessory olfactory bulbs as shown by the labelled glomeruli (Fig. 5). However, no labelling was found in the accessory olfactory bulbs of the vomeronasalectomized animals, 3 days or 1 month after nerve section, even though the dye was effectively incorporated in the vomeronasal neuroreceptors. This shows that section of the nerves was a reliable procedure for achieving deafferentation of the accessory olfactory bulbs and that no nerve regeneration had taken place 1 month later, i.e. at the time of odour stimulation.

\section{Discussion}

Our results indicate that the accessory olfactory pathway is not necessary for the neuroendocrine response of sexually experienced ewes to male odour since neither vomeronasal organ lesions nor nerve cuts inhibited the LH response. In both experiments, ram's wool induced increases of LH pulsatility in a similar proportion of control and vomeronasalectomized animals.

Persistence of the response can be attributed neither to incomplete destruction nor to regeneration of the vomeronasal system. Using an anterograde tracer (RITC), we have shown that the transport of the dye from the vomeronasal organs to the accessory olfactory bulbs was interrupted after nerve section. The transport was still interrupted 1 month after surgery which suggests 

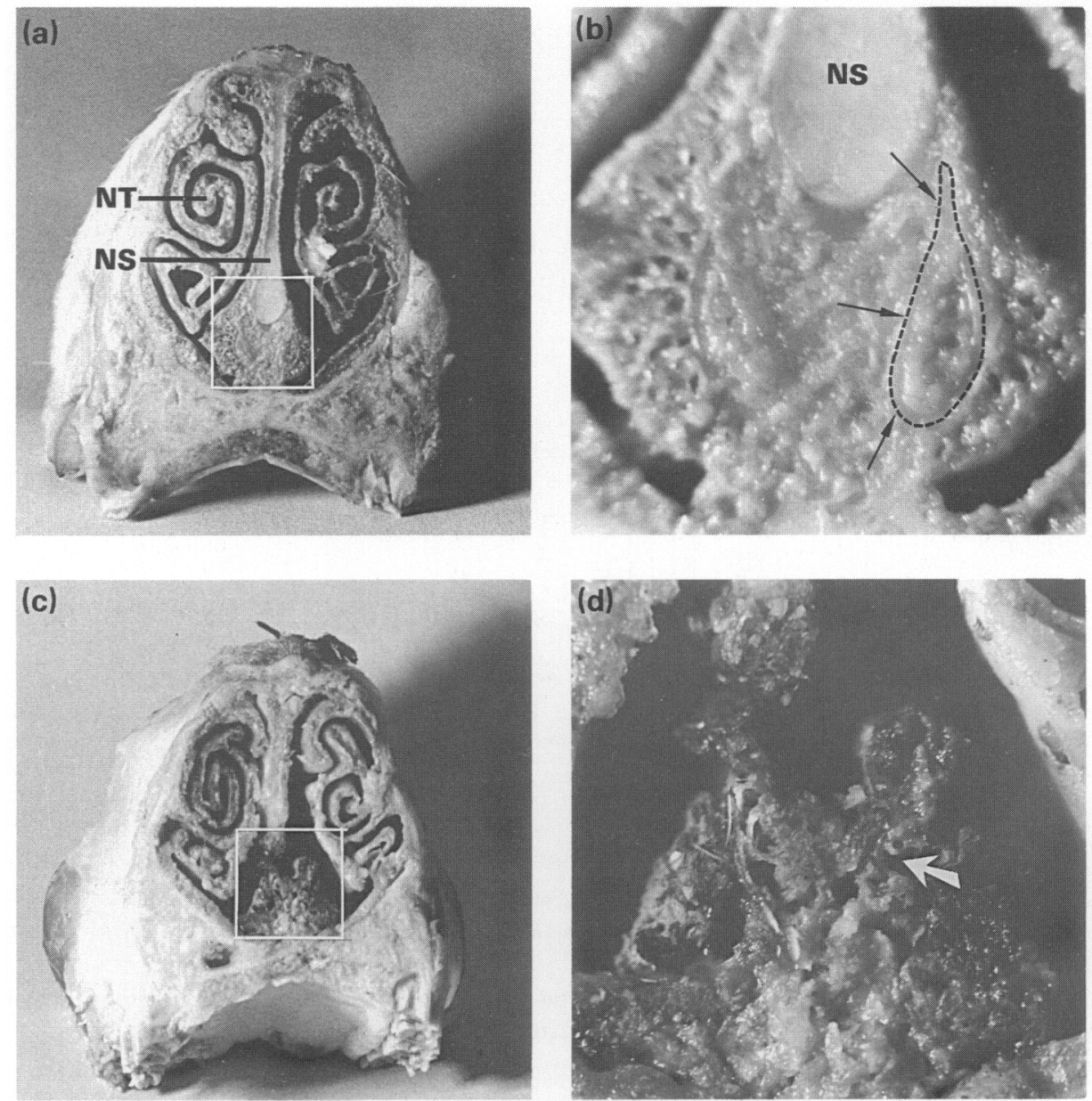

Fig. 3. Light micrographs of transverse sections through the nose of intact $(a, b)$ and vomeronasal lesioned (c, d) females. N.T. = nasal turbinate; N.S. = nasal septum. One of the vomeronasal organs of the intact subject is delimited by the broken line (b). For the operated animal, dissection was made 1 day after surgical electrocauterization and revealed obvious necrosis. a, c, Half normal size; $b, d, \times 2 \cdot 5$.

that no reinnervation of the accessory olfactory bulbs could have occurred at the time of odour stimulation. The absence of any long term regeneration was similarly noted in the mouse by Barber (1981) who observed that vacated post-synaptic sites in the accessory olfactory bulbs were not reinnervated for at least 5 months after operation. Examination of the noses of the sheep in Exp. I supports a complete lesioning of the accessory pathway since the whole vomeronasal neuroepithelium was burnt away. Finally, in both experiments, the glomerular layer of the accessory olfactory bulbs was profoundly damaged or even totally atrophied.

Unlike the accessory olfactory system, the main olfactory system was spared by the two surgical methods employed. Sections of the vomeronasal nerves were performed between and forward to the main olfactory bulbs. Very few if any olfactory nerves were damaged by surgery since the olfactory bulbs of sheep are widely separated when compared with rodents. Moreover, lesions of the vomeronasal organ, because of its anterior localization, completely spared the more dorsal olfactory mucosae. Indeed, olfactory discrimination was still present in all operated ewes as 

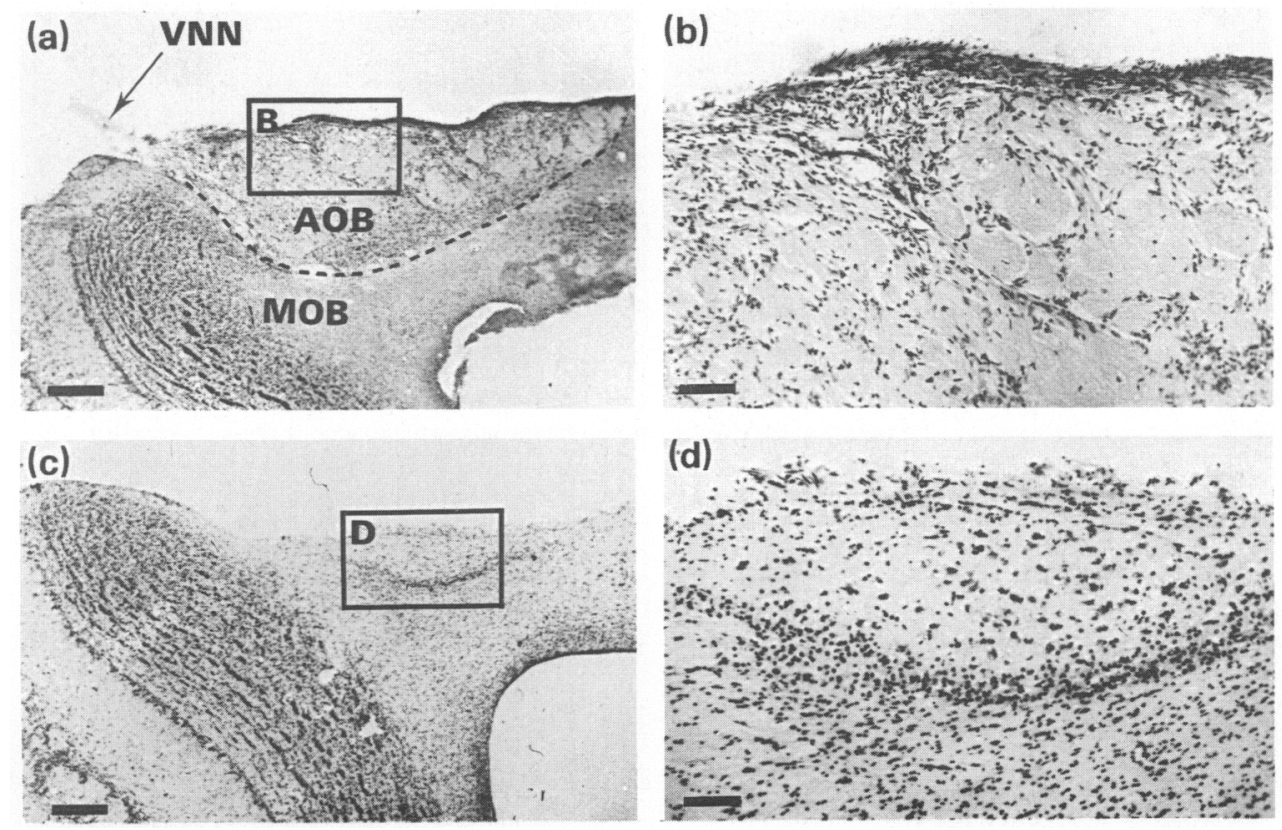

Fig. 4. Light micrographs of coronal sections through the accessory olfactory bulbs (AOB) of a sham-operated $(a, b)$ and an operated animal $(c, d)$ of Exp. I. For the sham-operated ewe, the AOB can be visualized lying on the dorsal part of the main olfactory bulb (MOB). The limits of the AOB are indicated by the broken line. The arrow indicates the afference of the vomeronasal nerve (VNN). Scale bar: $a, c=400 \mu \mathrm{m} ; b, d=100 \mu \mathrm{m}$.

measured by the behavioural test whereas it had been shown to disappear after bulbectomy (Cohen-Tannoudji et al., 1986) or after zinc sulphate treatment (Poindron, 1974) which selectively destroy the olfactory epithelium. This, together with the fact that the LH response of the ewes to ram's odour disappears after destruction of both accessory and main olfactory bulbs (CohenTannoudji et al., 1986), strongly suggests that this endocrine response is mediated by the main olfactory system.

This result is somewhat different from what has been observed in rodents in which endocrine responses to chemical signals have been reported to be mediated by the accessory olfactory system (Wysocki, 1979; Meredith, 1984). According to such results, it has been proposed that, in those species, the main and accessory system would constitute a dual functional system (Sanchez-Criado, 1982; Keverne, 1983). The vomeronasal system would be primarily involved in neuroendocrine responses to chemical cues whereas the main olfactory system would be preferentially concerned with sexual arousal and behaviour. Such an hypothesis has been reinforced by neuroanatomical studies which have demonstrated that the two systems have rather distinct central projections (Scalia \& Winans, 1976). The accessory olfactory bulbs are connected directly, via the amygdala, to hypothalamic areas that influence reproductive physiology. Such a consideration, as well as most experimental results, suggests that chemical stimulations act directly on the nervous structures involved in the control of reproductive endocrinology. In contrast, the main olfactory bulbs terminate more widely over the brain. In particular, they project to areas considered to be necessary for cognitive processing of sensory inputs. In taking this circuit, olfactory information may be modified by, or associated with the past experience of the subject before gaining access to those hypothalamic areas that control sexual physiology. In ewes, our results show the probable involvement of the main olfactory system in the mediation of $\mathrm{LH}$ response to male odour. According to 

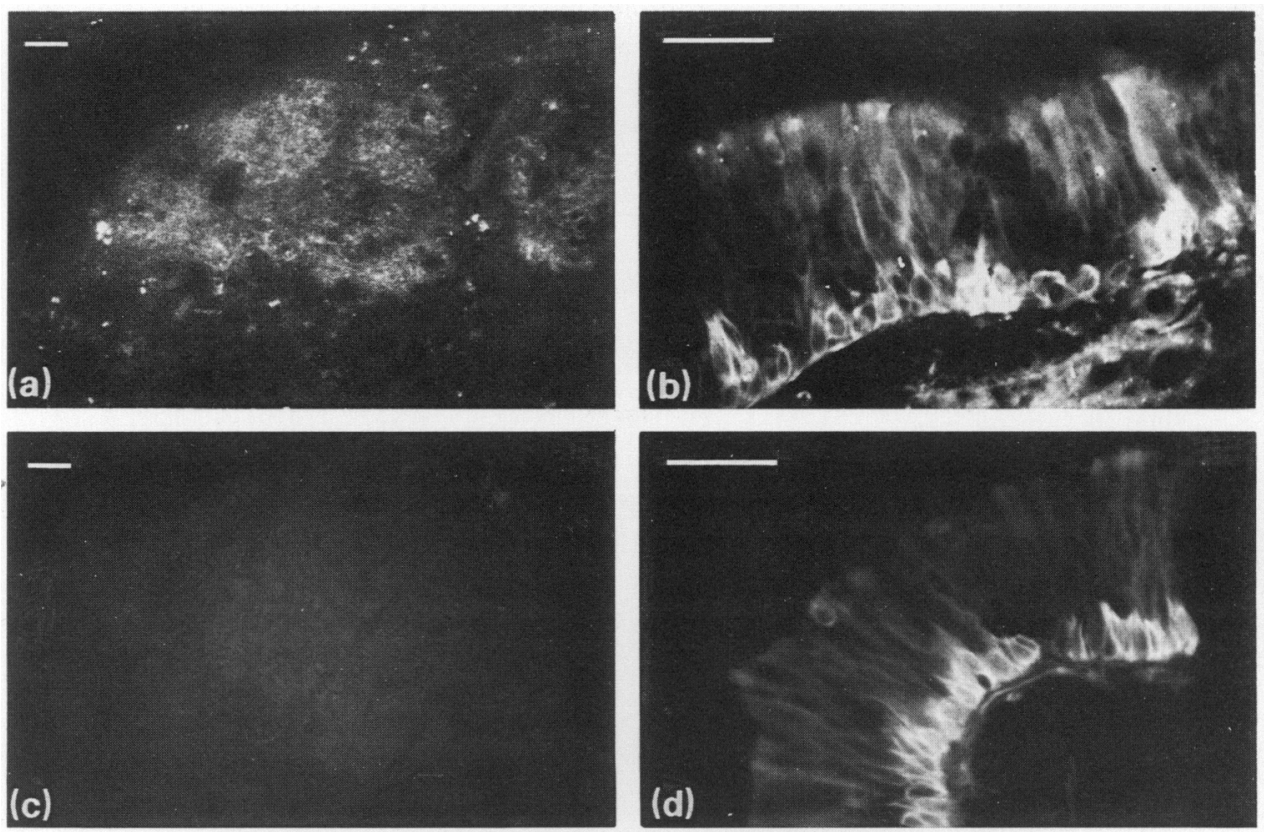

Fig. 5. Rhodamine staining of the accessory olfactory bulbs and organs of an intact (a, b) and an operated (c, d) (section of vomeronasal nerves) ewe. For the intact ewc, fluorescence can be observed both in the neuroreceptors of the vomeronasal organ (b) and in their endings located in the accessory bulb glomeruli (a). For the vomeronasalectomized ewe, fluorescence, although present in the vomeronasal neuroreceptors, was not visualized in the accessory bulbs, indicating that the vomeronasal pathway has been interrupted. Scale bar $=50 \mu \mathrm{m}$.

Keverne (1983) this could suggest a possible cognitive processing of olfactory inputs. In fact preliminary unpublished results do suggest a role for past experience in ewes: the ability of male chemosignals to elicit the neuroendocrine response is increased by short post-pubertal contact with the ram. However, nothing is known about the central projections of main, as well as accessory, olfactory bulbs in sheep. Neuroanatomical data would be of great interest, especially concerning the projections of the accessory olfactory bulbs, since they may reveal anatomical arrangements different from that of the rodents.

However, the involvement of the vomeronasal system cannot be ruled out: it could initially mediate the endocrine response but the main olfactory system may substitute for the vomeronasal system after animals have gained sexual experience. Such a mechanism has been observed in rodents when studying behavioural responses to chemical cues (Keverne et al., 1986; Meredith, 1986). In general though, endocrine responses appear not to be conditioned to olfactory stimuli; for example, the $\mathrm{LH}$ response of male mice disappears after vomeronasal lesions, even in animals that are sexually experienced (Coquelin et $a l ., 1984$ ). However, in sheep, other sensory cues are known to substitute for olfactory cues in producing the LH response (Cohen-Tannoudji et al., 1986), which clearly involves a higher order of neural processing. It is therefore perhaps not so surprising that this endocrine response may occur in the absence of the accessory olfactory system and be mediated, in these studies, by the main olfactory pathway.

In conclusion our resuls indicate that, in sheep, a rapid endocrine response to chemical cues can be mediated in the absence of the vomeronasal system, probably by the main olfactory pathway. In this species, the vomeronasal system is not necessary for the LH response of females to male odour. The exact role of the vomeronasal system in ungulates, especially in mediating physiological 
responses to chemosignals, remains to be determined. From our results, such species may represent a stage lying phylogenetically between rodents and primates, the former having an important functional vomeronasal system, while in many of the primates it is totally vestigial. In sheep, the accessory olfactory bulb is very small relative to the main bulb, and in line with this is a diminished significance for this sytem in neuroendocrine functioning and an ability of other sensory systems (main olfactory or visual) to substitute for this role.

We thank P. Orgeur and G. Venier for technical assistance and F. Jourdan for advice and help in histological procedures.

\section{References}

Barber, P.C. (1981) Regeneration of the vomeronasal nerves into the main olfactory bulb in the mouse. Brain. Res. 216, 239-25I.

Bellringer, J.F., Pratt, H.P. \& Keverne, E.B. (1980) Involvement of the vomeronasal organ and prolactin in pheromonal induction of delayed implantation in mice. J. Reprod. Fert. 59, 223-228.

Bronson, F.H. \& Whitten, W.K. (1968) Oestrusaccelerating pheromones of mice: assay, androgen dependency and presence in bladder urine. $J$. Reprod. Fert. 15, 131-134.

Bronson, F.H. \& Macmillan, B. (1984) Hormonal responses to primer pheromones. In Pheromones and Reproduction in Mammals, pp. 175-197. Ed. J. G. Vandenbergh. Academic Press, New York.

Cohen-Tannoudji, J., Locatelli, A. \& Signoret, J.P. (1986) Non pheromonal stimulation by the male of LH release in the anoestrous ewe. Physiol. Behav. 36, 921-924.

Colby, D.R. \& Vandenbergh, J.G. (1974) Regulatory effects of urinary pheromones on puberty in the mouse. Biol. Reprod. 11, 268-279.

Coquelin, A., Clancy, A.N., Macrides, F. \& Gorski, R.A. (1984) Pheromonally induced release of luteinizing hormone in male mice: involvement of the vomeronasal system. J. Neurosci. 4, 2230-2236.

Dominic, C.J. (1964) Source of the male odour causing pregnancy block in mice. J. Reprod. Fert. 8, 266-267.

Keverne, E.B. (1977) Pheromones and sexual behavior. In Handbook of Sexology, pp. 413-428. Eds J. Money \& H. Musaph. Elsevier/North Holland Biomedical Press, Amsterdam.

Keverne, E.B. (1983) Pheromonal influences on the endocrine regulation of reproduction. Trends in Neurosci. pp. 381-384.

Keverne, E.B., Hurphy, C.L., Wysocki, C.J. \& Meredith, M. (1986) Non-olfactory chemoreceptors of the nose: recent advances in understanding the vomeronasal and trigeminal systems. Chem. Senses 11, 119-133.

Knight, T.W. \& Lynch, P.R. (1980) Source of pheromones that stimulate ovulation in the ewe. Anim. Reprod. Sci. 3, 133-138.

Kratzing, J. (1971) The structure of the vomeronasal organ in the sheep. J. Anat. 108, 247-260.

Ladewig, J. \& Hart, B.L. (1981) Flehmen and vomeronasal organ function in male goats. Physiol. Behav. 24, 1067-1071.

Lomas, D.E. \& Keverne, E.B. (1982) Role of the vomeronasal organ and prolactin in the acceleration of puberty in female mice. J. Reprod. Fert. 66, 101-107.
Macrides, F.F., Fernandez, F. \& D'Angelo, W. (1974) Effects of exposure to vaginal odor and receptive females on plasma testosterone in the male hamster. Neuroendocrinology 15, 355-364.

Marchlewska-Koj, A. (1984) Pheromones and mammalian reproduction. Oxford Rev. Reprod. Biol. 6, 266-302.

Martin, G.B., Oldham, C.M. \& Lindsay, D.R. (1978) Increased plasma LH levels in seasonally anovular Merino ewes following the introduction of rams. Anim. Reprod. Sci. 3, 125-132.

Martin, G.B., Scaramuzzi, R.J. \& Henstridge, J.D. (1983) Effects of oestradiol, progesterone and androstenedione on the pulsatile secretion of luteinizing hormone in ovariectomized ewes during spring and autumn. J. Endocr. 96, 181-193.

Maruniak, J.A. \& Bronson, F.H. (1976) Gonadotropic responses of male mice to female urine. Endocrinology 99, 963-969.

Meredith, M. (1984) Sensory physiology of pheromone communication. In Pheromones and Reproduction in Mammals, pp. 200-245. Ed. J. G. Vandenbergh. Academic Press, New York.

Meredith, M. (1986) Vomeronasal organ removal before sexual experience impairs male hamster mating behavior. Physiol. Behav. 36, 737-743.

Montgomery, G.W., Martin, G.B. \& Pelletier, J. (1985) Changes in pulsatile $\mathbf{L H}$ secretion after ovariectomy in Ile-de-France ewes in two seasons. J. Reprod. Fert. $73,173-183$.

Pelletier, J., Kann, G., Dolais, J. \& Rosselin, G. (1968) Dosage radioimmunologique de l'hormone lutéinisante plasmatique chez le mouton. C. r. hebd. Séanc. Acad. Sci. Paris D 266, 2291-2294.

Pelletier, J., Garnier, D.H., de Reviers, M.M., Terqui, M. \& Ortavant, R. (1982) Seasonal variation in $\mathrm{LH}$ and testosterone release in rams of two breeds. $J$. Reprod. Fert. 64, 341-346.

Poindron, P. (1974) Méthode de suppression réversible de l'odorat chez la brebis et vérification de l'anosmie au moyen d'une épreuve comportementale. Annls Biol. anim. Biochim. Biophys. 14, 411-415.

Poindron, P., Cogniè, Y., Gayerie, F., Orgeur, P., Oldham, C.M. \& Ravault, J.P. (1980) Changes in gonadotrophins and prolactin levels in isolated (seasonally or lactationally) anovular ewes associated with ovulation caused by the introduction of rams. Physiol. Behav. 25, 227-236.

Reynolds, J.M. \& Keverne, E.B. (1979) The accessory olfactory system and its role in pheromonally 
mediated suppression of oestrus. J. Reprod. Fert. 57 , 31-35.

Sanchez-Criado, J.E. (1982) Involvement of the vomeronasal system in the reproduction physiology of the rat. In Olfaction and Endocrine Regulation, pp. 209-221. Ed. W. Breipohl. IRL Press. London.

Scalia, F. \& Winans, S.S. (1976) New perspectives on the morphology of the olfactory system: olfactory and vomeronasal pathways in Mammals. In Mammalian Olfaction, Reproductive Processes, and Behavior, pp. 8-26. Ed. R. L. Doty. Academic Press, New York.

Siegel, H.S. (1956) Non-parametric Statistics for the Behavioral Sciences. McGraw Hill, New York.

Signoret, J.P. \& Lindsay, D.R. (1982) The male effect in domestic mammals: effect on LH secretion and ovulation. Importance of olfactory cues. In Olfaction and Endocrine Regulation, pp. 63-72. Ed. W. Breipohl. IRL Press. London.
Terqui, M. \& Thimonier, J. (1975) Nouvelle méthode radioimmunologique pour l'estimation du niveau de progestérone plasmatique. Application pour le diagnostic précoce de la gestation chez la brebis et la chèvre. C. r. hebd. Séanc. Acad. Sci., Paris D $\mathbf{2 8 0}$, 2789-2792.

Thanos, S., Vidal-Sanz, M. \& Aguayo, A.J. (1987) The use of rhodamine. B. isothiocyanate (RITC) as an anterograde and retrograde tracer in the adult rat visual system. Brain Res. 406, 317-321.

Wysocki, C.J. (1979) Neurobehavioral evidence for the involvement of the vomeronasal system in mammalian reproduction. Neuroscience \& Biobehavioral Reviews 3, 301-341.

Wysocki, C.J., Katz, Y. \& Bernhard, R. (1983) Male vomeronasal organ mediates female-induced testosterone surges in mice. Biol. Reprod. 28, 971-922.

Received 15 July 1988 